\title{
Socio-demographic determinants of beliefs about COVID-19 vaccine in Nigeria
}

\author{
Chinonyerem Ogadi IHEANACHO $^{1 *}$ (D) , Okechukwu Harrison ENECHUKWU ${ }^{2}$ (D), \\ Chinelo Nneka AGUIYI-IKEANYI 3 (D) \\ 1 Department of Clinical Pharmacy and Public health, Faculty of Pharmacy, University of Calabar, Calabar, \\ Nigeria. \\ 2 Department of Pharmaceutical Services, Landmark University medical Centre, Landmark University, Omu-aran, \\ Nigeria \\ 3 Department of Clinical Pharmacy and Pharmacy Management, Faculty of Pharmaceutical Sciences, University \\ of Nigeria, Nsukka, Nigeria \\ * Corresponding Author. E-mail: nonye2m@yahoo.com (C.O.I.); Tel. +234-803-792 3560.
}

Received: 18 May 2021 / Revised: 07 June 2021/ Accepted: 20 June 2021

\begin{abstract}
Successful implementation of COVID-19 vaccines may be influenced by beliefs about it. This study assessed beliefs about COVID-19 vaccine in Nigeria and associated socio-demographic characteristics. It also evaluated socio-demographics as a predictive model for beliefs about the vaccine. This will provide insight to effective vaccine implementation measures. A cross-sectional online survey was conducted among 410 participants. A two-part questionnaire was developed using Google forms and validated by pre-testing and face validity. The internet link was distributed through snow ball approach to consenting participants from the six geopolitical zones through online platforms. Descriptive statistics and binary logistic regression analysis were conducted using SPSS version 24 and statistical significance was set as $\mathrm{p} \leq 0.05$. A total of 410 respondents participated in the study. Total weighted beliefs about COVID-19 vaccine showed that the majority 337 (82.20\%) had positive beliefs about the vaccine, and this was associated with geopolitical region $(p=0.002)$ and educational qualification $(p=0.005)$. Socio-demographic characteristics was also found to be highly predictive of beliefs about the vaccine (68\%). Socio-demographics predicts beliefs about COVID-19 with relatively high accuracy. Positive beliefs was mostly found, and this was associated with geopolitical region and educational qualification. Positive beliefs about the vaccine may enhance vaccine acceptance and cause a break in transmission dynamics of SARS-Cov-2 infection.
\end{abstract}

KEYWORDS: COVID-19 Vaccine; socio-demographic characteristics; SARS-CoV-2; Nigeria; beliefs predictive model.

\section{INTRODUCTION}

Coronavirus Disease 2019 (COVID-19) is an ongoing pandemic of highly infectious characteristic, and has resulted in several morbidities and mortalities [1,2]. Although, several drugs have been associated with improved outcomes of COVID-19 [3,4], it still remains a major public health problem as no specific drug is yet clinically proven and approved for its cure. The use of vaccines is a potential effective means of achieving control of the pandemic. Therefore, research towards finding a safe and efficacious COVID-19 vaccine have been a major priority. Meanwhile, there appears to be several beliefs and perceptions about the vaccine and these have led to a rise in the vaccine hesitancy [5]. Perceptions and beliefs are psychosocial characteristics that influence behaviours and attitudes in diverse ways. The high tendency for generalised beliefs and perceptions on COVID-19 vaccine within a community, as a result of social / peer environment influences [6] is an important concern. This is because the acceptance of the vaccine may be reliant on beliefs associated with it [7].

Meanwhile, previous reports have suggested that beliefs and personal perception about COVID-19 could be a predictor of attitude towards the vaccine and its acceptability [5,8]. Some psycho-social factors noted to influence vaccine acceptance include perception of need, confidence in vaccine or source and convenience [6]. Other identified influencing factors of belief about the vaccine are religion [9], age and gender

How to cite this article: Iheanacho $\mathrm{CO}$, Enechukwu $\mathrm{OH}$, Aguiyi-Ikeanyi CN. Socio-demographic determinants of beliefs about COVID-19 vaccine in Nigeria. J Res Pharm. 2021; 25(6): 872-880. 
[7]. Therefore, negative beliefs about COVID-19 vaccine may be associated with socio-demographic characteristics of the population, and this may potentially influence the willingness to accept the vaccine.

Conspiracy beliefs is associated with negative attitudes towards vaccination [10], and this has been previously observed in Nigeria over poliomyelitis vaccine [11]. Nigeria was hence the last country in Africa to be declared free of wild poliovirus by the World Health Organisation in June, 2020 [12], this therefore raises concerns over beliefs about COVID-19 vaccine in Nigeria. Religious beliefs is another major influence of health behaviours and practices of Nigerians towards diseases, including COVID-19 [13]. Beliefs could result in the relegation of relevant medical care and life-saving procedures [14]. It could also influence differences in vaccine coverage between countries and cause a potential delay in global control of the COVID-19 pandemic. It is hence, paramount to understand the beliefs of Nigerians towards COVID-19 vaccine, to enable appropriate approaches in its implementation in Nigeria.

Socio-demographic characteristics is a likely major determinant of beliefs about COVID-19 vaccine. This study assessed beliefs about COVID-19 vaccine and socio-demographic associations of beliefs about the vaccine. It also evaluated socio-demographic characteristics as a predictive model for beliefs about COVID-19 vaccine in Nigeria. This will equip public health professionals and policy makers with insight and relevant information for effective measures of COVID-19 vaccine implementation.

\section{RESULTS}

\subsection{Respondents' socio-demographics}

A total of 410 respondents participated in the survey, and using the Cronbach's alpha, the survey tool was found to have a reliability of 0.762 . Study participants were mostly males 241 (58.78 \%), single 240 (58.54 $\%)$ and employed 301 (73.41\%). Similarly, almost all the participants had tertiary education 371 (90.45\%), and a higher proportion of the respondents were from the North-central $133(32.44 \%)$, and were between $26-35$ years old 175, (42.68 \%). Only $8(2.0 \%)$ were above 55 years old, and $18(4.4 \%)$ made up 46-55 years age range. See Table 1.

\subsection{Beliefs about COVID-19 vaccine}

Table 2 shows the respondents' belief about COVID-19 vaccine. A large majority did not believe COVID19 vaccine to be a conspiracy 331 (80.73\%), and also did not belief it will not be effective against the SARSCoV-2, 347 (84.63\%). Similarly, majority reported that religious beliefs will not prevent them from taking the vaccine $352(85.85 \%)$. Also, over half $240(58.54 \%)$ of the study participants did not belief their immunity to be more protective than a COVID-19 vaccine, and $253(61.71 \%)$ did not consider the vaccine to be unsafe or have mistrust of the government's intention. The total weighted belief about the vaccine showed that majority $337(82.20 \%)$ had positive beliefs about the vaccine.

\subsection{Socio-demographic association of beliefs about COVID-19 vaccine}

Socio-demographic associations of beliefs about COVID-19 vaccines is shown in Table 3. The study noted that no significant difference was found in beliefs about COVID-19 vaccine in Gender $(\mathrm{p}=0.584)$, Age $(p=0.968)$, Marital status $(p=0.918)$ and Employment status $(p=0.744)$. However, educational qualifications had a statistically significant association with the beliefs $(p=0.005)$. Geo-political region also showed statistical significance in the difference in beliefs of the vaccine among the respondents $(p=0.002)$.

Socio-demographic determinants of belief about COVID-19 vaccine were evaluated and highlighted. Using available demographic information, the best model that determines beliefs about COVID-19 vaccine had age, gender, marital status, employment status, educational qualifications and geo-political region as explanatory variables. The ROC showed a predictive probability of area under the curve (AUC) of 0.68 (68 \%) with Confidence Interval (CI) of $0.613-0.742$ and $\mathrm{p}<0.001$. (Table 4; Figure 1).

\section{DISCUSSION}

This study revealed critical findings regarding the socio-demographic determinants of beliefs about COVID-19 vaccine in Nigeria. Through statistical analyses, it showed significant associations between regions and educational qualification with beliefs about the vaccine, making them likely predictors of beliefs about the vaccine.

The study found positive beliefs about COVID-19 vaccine in a large majority of the study participants. This was consistent with a previous study in Italy, where positive perception about the 
vaccine was mostly reported [17]. In contrast, only one third of participants of a previous study in Saudi Arabia had positive beliefs about the vaccine [7]. Beliefs about vaccine may influence its acceptance [18], and is responsible for hesitation in several countries $[7,18,19]$. The positive beliefs found in our study may be related to the regular and consistent public health awareness in the country concerning the vaccine, via several media. Positive perception of vaccine has been previously reported as a major predictor of vaccine acceptance among Nigerians [20]. This may imply probability of high vaccine acceptance in the country however, it is noteworthy that other psycho-social attributes may also actively influence acceptance of the vaccine.

Table 1. Socio-demographics of respondents.

\begin{tabular}{|c|c|c|}
\hline Variables & $\begin{array}{c}\text { Frequency } \\
(n=410)\end{array}$ & Percentage $(\%)$ \\
\hline \multicolumn{3}{|l|}{ Gender } \\
\hline Male & 241 & 58.78 \\
\hline Female & 169 & 41.22 \\
\hline \multicolumn{3}{|l|}{ Age } \\
\hline 18 - 25 years & 117 & 28.54 \\
\hline 26 - 35 years & 175 & 42.68 \\
\hline 36 - 45 years & 90 & 21.95 \\
\hline 46 - 55 years & 18 & 4.39 \\
\hline$>55$ years & 8 & 1.95 \\
\hline $\mathrm{N} / \mathrm{A}$ & 2 & 0.49 \\
\hline \multicolumn{3}{|l|}{ Marital status } \\
\hline Married & 167 & 40.73 \\
\hline Single & 240 & 58.54 \\
\hline Widowed & 1 & 0.24 \\
\hline Divorced & 1 & 0.24 \\
\hline Separated & 1 & 0.24 \\
\hline \multicolumn{3}{|l|}{ Employment status } \\
\hline Employed & 301 & 73.41 \\
\hline Unemployed & 3 & 0.73 \\
\hline Student & 86 & 20.98 \\
\hline Retiree & 3 & 0.73 \\
\hline $\mathrm{N} / \mathrm{A}$ & 17 & 4.15 \\
\hline \multicolumn{3}{|c|}{ Highest educational qualification } \\
\hline None & 1 & 0.24 \\
\hline Primary & 0 & 0.00 \\
\hline Secondary & 34 & 8.29 \\
\hline Tertiary & 371 & 90.49 \\
\hline Informal & 1 & 0.24 \\
\hline $\mathrm{N} / \mathrm{A}$ & 3 & 0.73 \\
\hline \multicolumn{3}{|l|}{ Geo-political zones } \\
\hline North-east & 15 & 3.66 \\
\hline North-west & 16 & 3.90 \\
\hline North-central & 133 & 32.44 \\
\hline South-east & 38 & 9.27 \\
\hline South-west & 89 & 21.71 \\
\hline South-south & 114 & 27.80 \\
\hline $\mathrm{N} / \mathrm{A}$ & 5 & 1.22 \\
\hline
\end{tabular}

In congruence with previous findings from Saudi Arabia [7], COVID-19 vaccine was not believed to be associated with conspiracy theories by the majority of our study participants. Conspiracy theories attempt to induce rejection of standard and scientific events and procedures, by insinuating the association of hidden plots to the events. Although exposure to COVID-19 vaccine conspiracy theory is almost universal, the extent of its belief and the potential proportion of believers in Nigeria has been elucidated in our study. Unlike for poliomyelitis vaccines where uptake was resisted in some parts of Nigeria as a result of conspiracy theories [11], findings from our study show less of this for COVID-19 vaccine. The nature of the pandemic may have contributed to the observed positive beliefs about the vaccine. Being a potential major public health threat, conspiracy theories are recognised to influence COVID-19 vaccine hesitancy [19]. This is suggestive of the need 
for more rigorous public health intervention with specific and targeted information in various parts of the world.

Table 2. Beliefs about COVID-19 Vaccine in Nigeria.

\begin{tabular}{|c|c|c|c|c|}
\hline Variables & Belief & & $\begin{array}{c}\text { Frequency }(\mathrm{n}= \\
410)\end{array}$ & $\begin{array}{c}\text { Percentage } \\
(\%)\end{array}$ \\
\hline \multirow[t]{2}{*}{ COVID-19 vaccination is a conspiracy } & Negative & 1 & 79 & 19.27 \\
\hline & Positive & 0 & 331 & 80.73 \\
\hline \multirow[t]{2}{*}{$\begin{array}{l}\text { The COVID-19 vaccine will not be effective at preventing } \\
\text { the disease. }\end{array}$} & Negative & 1 & 63 & 15.37 \\
\hline & Positive & 0 & 347 & 84.63 \\
\hline \multirow[t]{3}{*}{$\begin{array}{l}\text { My immunity will better protect me against COVID-19 } \\
\text { than the vaccine. }\end{array}$} & Negative & 1 & 169 & 41.22 \\
\hline & Positive & 0 & 240 & 58.54 \\
\hline & No response & & 1 & 0.24 \\
\hline \multirow[t]{3}{*}{$\begin{array}{l}\text { The COVID }-19 \text { vaccine is not as safe as Government may } \\
\text { want us to believe. }\end{array}$} & Negative & 1 & 156 & 38.05 \\
\hline & Positive & 0 & 253 & 61.71 \\
\hline & No response & & 1 & 0.24 \\
\hline \multirow[t]{3}{*}{$\begin{array}{l}\text { My religious belief may prevent me from taking a } \\
\text { COVID-19 vaccine }\end{array}$} & Negative & 1 & 56 & 13.66 \\
\hline & Positive & 0 & 352 & 85.85 \\
\hline & No response & & 2 & 0.49 \\
\hline \multirow[t]{2}{*}{ Total weighted belief } & Negative & 1 & 73 & 17.80 \\
\hline & Positive & 0 & 337 & 82.20 \\
\hline
\end{tabular}

* weighted negative belief $\geq 3(=1)$, Positive belief $\leq 2(=0)$

Findings from our study also showed religious beliefs did not influence negative beliefs about the vaccine in a large majority of the study participants. The finding was unexpected as previous reports showed that religious beliefs influenced COVID-19 behaviours [13], and acceptance of poliomyelitis vaccine [11] in Nigeria. Being a highly religious nation, Nigerian religious leaders are highly respected and influential in shaping beliefs and attitudes, making them crucial in information dissemination among the population [21]. Meanwhile, religious beliefs was an identified reason for vaccine hesitancy among Irish and UK citizens [19]. Involvement of religious leaders in the dissemination of appropriate and correct information about the vaccine may be a potent tool for enhanced perception about the vaccine.

The vaccine was believed to be more protective than the natural immunity by our study participants. Meanwhile, vaccines were considered unnecessary in a previous study by a quarter of vaccine refusers, this was related to their perception of adequate adherence to the COVID-19 safety protocols and health status [7]. Eventual control of COVID-19 may largely depend on beliefs about the effectiveness of COVID-19 vaccines in preventing the disease. Higher COVID-19 literacy is essential for achieving the needed vaccine-related actions among the populace.

In our study, COVID-19 vaccine was mostly believed to be as safe as the government portrays it to be. This was similar to findings in India [22,23]. This finding suggests that potential vaccine hesitancy in Nigeria may not be associated with mistrust in government. Given lessons from previously long-lasting belief-induced distortion of poliomyelitis vaccination in Nigeria, gaining public trust and confidence will likely remain an essential need of the government. Meanwhile, mistrust in the government was a reason for vaccine hesitancy in Irish and UK [19]. Mistrust in government will likely result in beliefs of alternative explanations to events. Also respondents in a previous study were mostly not certain of the safety of a COVID-19 vaccine [7] and this was a reason for hesitation among nurses in Hong Kong [18]. Transparency and timely information may positively influence trust, and are essential tools to promote beliefs. 
Table 3. Socio-demographic Associations of Beliefs about COVID-19 Vaccine in Nigeria.

\begin{tabular}{|c|c|c|c|c|c|}
\hline Variables & Total $(n=410)$ & $\begin{array}{c}\text { Positive belief } n \\
(\%)\end{array}$ & $\begin{array}{c}\text { Negative belief } n \\
(\%)\end{array}$ & $x^{2}$ & p-value \\
\hline Gender & & & & 0.301 & 0.584 \\
\hline Male & 241 & $196(81.33)$ & 45 (18.67) & & \\
\hline Female & 169 & $141(83.43)$ & $28(16.57)$ & & \\
\hline Age & & & & 0.936 & 0.968 \\
\hline 18 - 25 years & 117 & $96(82.05)$ & 21 (17.95) & & \\
\hline 26 - 35 years & 175 & $143(81.71)$ & $32(18.29)$ & & \\
\hline 36 - 45 years & 90 & 75 (83.33) & 15 (16.67) & & \\
\hline 46 - 55 years & 18 & $14(77.78)$ & $4(22.22)$ & & \\
\hline$>55$ years & 8 & 7 (87.50) & $1(12.50)$ & & \\
\hline $\mathrm{N} / \mathrm{A}$ & 2 & $2(100.00)$ & $0(0.00)$ & & \\
\hline Marital status & & & & 0.945 & 0.918 \\
\hline Married & 167 & $135(80.84)$ & $32(19.16)$ & & \\
\hline Single & 240 & 199 (82.92) & 41 (17.08) & & \\
\hline Widowed & 1 & $1(100.00)$ & $0(0.00)$ & & \\
\hline Divorced & 1 & $1(100.00)$ & $0(0.00)$ & & \\
\hline Separated & 1 & $1(100.00)$ & $0(0.00)$ & & \\
\hline Employment status & & & & 1.954 & 0.744 \\
\hline Employed & 301 & $247(82.06)$ & 54 (17.94) & & \\
\hline Unemployed & 3 & $3(100.00)$ & $0(0.00)$ & & \\
\hline Student & 86 & $69(80.23)$ & 17 (19.77) & & \\
\hline Retiree & 3 & $3(100.00)$ & $0(0.00)$ & & \\
\hline $\mathrm{N} / \mathrm{A}$ & 17 & $15(88.24)$ & $2(11.76)$ & & \\
\hline $\begin{array}{l}\text { Highest educational } \\
\text { qualification }\end{array}$ & & & & 14.995 & $0.005^{*}$ \\
\hline None & 1 & $0(0.00)$ & $1(100.00)$ & & \\
\hline Primary & 0 & $0(0.00)$ & $0(0.00)$ & & \\
\hline Secondary & 34 & $4(11.76))$ & $30(88.24)$ & & \\
\hline Tertiary & 371 & $306(82.48)$ & 65 (17.52) & & \\
\hline Informal & 1 & $0(0.00)$ & $1(100.00)$ & & \\
\hline $\mathrm{N} / \mathrm{A}$ & 3 & $1(33.33)$ & $2(66.67)$ & & \\
\hline Geo-political zones & & & & 20.616 & $0.002^{*}$ \\
\hline North-east & 15 & $10(66.67)$ & $5(33.33)$ & & \\
\hline North-west & 16 & $12(75.00)$ & $4(25.00)$ & & \\
\hline North-central & 133 & 115 (86.47) & $18(13.53)$ & & \\
\hline South-east & 38 & $28(73.68)$ & $10(26.32)$ & & \\
\hline South-west & 89 & $82(92.13)$ & $7(7.87)$ & & \\
\hline South-south & 114 & 88 (77.19) & $26(22.81)$ & & \\
\hline $\mathrm{N} / \mathrm{A}$ & 5 & $2(40.00)$ & $3(60.00)$ & & \\
\hline
\end{tabular}

*Statistically significant, N/A: Not Available

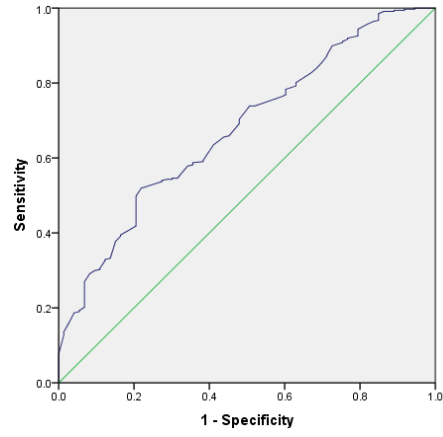

Figure 1. ROC curve for the model (Beliefs about COVID-19 vaccine $)=\beta$ o $+\beta 1$ age $(18-25)+\beta 2$ age $(26-$ $35)+\beta 3$ age $(36-45)+\beta 4$ age $(46-55)+\beta 5$ age $(55+)+\beta 6$ gender $+\beta 7$ marital status $+\beta 8$ employment status (employed) $+\beta 9$ employment status (unemployed) $+\beta 10$ employment status (student) $+\beta 11$ employment status (retired) $+\beta 12$ educational qualification (none) $+\beta 13$ educational qualification (primary) $+\beta 14$ educational qualification (secondary) $+\beta 15$ educational qualification (tertiary) $+\beta 16$ geopolitical region (north-east) $+\beta 16$ geopolitical region (north-west ). Diagonal segments are produced by ties. 
Table 4. Socio-demographic Determinants of Beliefs about COVID-19 Vaccine Using Binary Logistic Regression.

\begin{tabular}{|c|c|c|c|c|c|c|c|}
\hline \multirow{2}{*}{$\begin{array}{l}\text { Variables } \\
\text { Gender }\end{array}$} & \multirow[t]{2}{*}{$\begin{array}{c}\text { Frequency } \\
(\mathrm{n}=410)\end{array}$} & \multirow[t]{2}{*}{$\begin{array}{c}\text { Percentage } \\
\%\end{array}$} & \multirow[t]{2}{*}{ OR } & \multirow[t]{2}{*}{ SE } & \multicolumn{2}{|c|}{$95 \% \mathrm{CI}$} & \multirow[t]{2}{*}{$P$} \\
\hline & & & & & Lower & Upper & \\
\hline Male & 241 & 58.78 & $R E F$ & $R E F$ & $R E F$ & $R E F$ & $R E F$ \\
\hline Female & 169 & 41.22 & 1.131 & 0.297 & 0.633 & 2.023 & 0.678 \\
\hline \multicolumn{8}{|l|}{ Age (years) } \\
\hline $18-25$ & 117 & 28.54 & $R E F$ & $R E F$ & $R E F$ & $R E F$ & $R E F$ \\
\hline $26-35$ & 175 & 42.68 & 1.221 & 0.504 & 0.455 & 3.282 & 0.692 \\
\hline $36-45$ & 90 & 21.95 & 1.57 & 0.64 & 0.448 & 5.505 & 0.481 \\
\hline $46-55$ & 18 & 4.39 & 1.446 & 0.847 & 0.275 & 7.596 & 0.663 \\
\hline$>55$ & 8 & 1.95 & 1.483 & 1.274 & 0.122 & 18.016 & 0.757 \\
\hline $\mathrm{N} / \mathrm{A}$ & 2 & 0.49 & $1.34 \mathrm{E}+09$ & 26856.53 & 0 & . & 0.999 \\
\hline \multicolumn{8}{|l|}{ Marital status } \\
\hline Married & 167 & 40.73 & $R E F$ & $R E F$ & $R E F$ & $R E F$ & REF \\
\hline Single & 240 & 58.54 & 1.216 & 0.378 & 0.579 & 2.553 & 0.605 \\
\hline Widowed & 1 & 0.24 & 1.777 & 49221.54 & 0 & . & 1 \\
\hline Divorced & 1 & 0.24 & $8.32 \mathrm{E}+08$ & 40192.97 & 0 & . & 1 \\
\hline Separated & 1 & 0.24 & $3.81 \mathrm{E}+08$ & 40192.97 & 0 & . & 1 \\
\hline \multicolumn{8}{|l|}{$\begin{array}{l}\text { Employment } \\
\text { status }\end{array}$} \\
\hline Employed & 301 & 73.41 & REF & $R E F$ & $R E F$ & $R E F$ & $R E F$ \\
\hline Unemployed & 3 & 0.73 & $4.99 \mathrm{E}+08$ & 22676.44 & 0 & . & 0.999 \\
\hline Student & 86 & 20.98 & 0.767 & 0.492 & 0.292 & 2.012 & 0.589 \\
\hline Retiree & 3 & 0.73 & $1.32 \mathrm{E}+08$ & 28412.77 & 0 & . & 0.999 \\
\hline $\mathrm{N} / \mathrm{A}$ & 17 & 4.15 & 1.114 & 0.81 & 0.228 & 5.451 & 0.894 \\
\hline \multicolumn{8}{|l|}{$\begin{array}{l}\text { Highest } \\
\text { educational } \\
\text { qualification }\end{array}$} \\
\hline None & 1 & 0.24 & $R E F$ & $R E F$ & $R E F$ & $R E F$ & $R E F$ \\
\hline Primary & 0 & 0.00 & - & - & - & - & - \\
\hline Secondary & 34 & 8.29 & $1.02 \mathrm{E}+09$ & 40193.65 & 0 & . & 1 \\
\hline Tertiary & 371 & 90.49 & $5.16 \mathrm{E}+08$ & 40193.65 & 0 & . & 1 \\
\hline Informal & 1 & 0.24 & 0.105 & 56841.93 & 0 & . & 1 \\
\hline $\mathrm{N} / \mathrm{A}$ & 3 & 0.73 & 64456482 & 40193.65 & 0 & . & 1 \\
\hline \multicolumn{8}{|l|}{$\begin{array}{l}\text { Geo-political } \\
\text { zones }\end{array}$} \\
\hline North-east & 15 & 3.66 & $R E F$ & $R E F$ & $R E F$ & REF & $R E F$ \\
\hline North-west & 16 & 3.90 & 1.446 & 0.835 & 0.282 & 7.43 & 0.659 \\
\hline North-central & 133 & 32.44 & 3.767 & 0.667 & 1.019 & 13.925 & 0.047 \\
\hline South-east & 38 & 9.27 & 1.653 & 0.715 & 0.407 & 6.712 & 0.482 \\
\hline South-west & 89 & 21.71 & 6.303 & 0.72 & 1.538 & 25.832 & 0.011 \\
\hline South-south & 114 & 27.80 & 1.93 & 0.643 & 0.547 & 6.812 & 0.307 \\
\hline $\mathrm{N} / \mathrm{A}$ & 5 & 1.22 & 0.245 & 1.423 & 0.015 & 3.978 & 0.322 \\
\hline
\end{tabular}

A large majority of our study participants also believed in the effectiveness of the vaccine for COVID19 prevention. Conversely, the majority of vaccine hesitant in India did not believe in its effectiveness [22], and participants in a Saudi Arabian study were mostly unsure of its effectiveness [7]. Also, efficacy and effectively were reported reasons for vaccine hesitancy in Hong Kong [18]. These observed perceptions of ineffectiveness of the vaccine, from other studies is an indication of the need for more public awareness messaging on the vaccine. Meanwhile, the rolled out vaccines have shown high effectiveness in the general population of various countries [24].

Our study shows that beliefs about COVID-19 vaccine can be predicted with relatively high accuracy by readily available socio-demographic information. This encourages the relevance of socio-demographic model in the determination of beliefs. In Nigeria, persons and regions of low literacy have been clearly noted to show mistrust or negative belief about vaccine [11]. Religion was associated with beliefs about COVID-19 
in a Canadian study [9]. Socio-demographic distribution of persons may therefore, be predictors of the vaccine uptake.

In this study, socio-demographic characteristics such as age, gender, marital status and employment status were not associated with beliefs about the vaccine. A similar finding was also reported by Biasio et al. in a previous study in Italy [17]. Meanwhile, geo-political region and educational qualification were associated with beliefs about the vaccine in our study. Geo-graphical location has been previously noted to be associated with beliefs about vaccines in Nigeria [11], and this may not be unrelated to the educational disparity in the regions of the country.

The study elicits belief-factors about COVID-19 vaccine in Nigeria, which may invariably influence vaccine acceptance in the country. It also elucidated the demographic profile and characteristics likely to influence notable beliefs about the vaccine and this, to the best of our knowledge is the first study to perform this assessment in the country. However, the study design may have excluded rural dwellers and older persons who may not have had access to internet facilities or who may not be users of social media applications. Also, the merging of "undecided" group with "disagree" and "strongly disagree" groups may have resulted in losses of some statistical outcomes during categorisation of beliefs about COVID-19 vaccine.

\section{CONCLUSION}

Positive beliefs about COVID-19 vaccine was mostly found among the study participants, and this was significantly associated with geopolitical region and educational qualification of the participants. Sociodemographic characteristics was also seen to be a relatively high predictive model for beliefs about COVID19 vaccine. Although positive beliefs was mostly seen, the observed educational and geographical variations in beliefs is suggestive of careful attention for targeted messaging. Improved beliefs about the vaccine may invariably enhance vaccine acceptance and cause a break in transmission dynamics of SARS-Cov-2 infection.

\section{MATERIALS AND METHODS}

\subsection{Study design and study setting}

A cross-sectional online survey was performed from 16 December 2020 to 10 January 2021 among 410 adults in Nigeria. Nigeria is the most populous black nation, located in Sub-Saharan Africa with a middleincome, and an area of 923, 768 square kilometre. It is made up of a population of about 200 million and six geo-political zones which are: South-south, South-east, South-west, North-east, North-west and North-central.

\subsection{Study population}

The study was conducted among adult Nigerians in the six geopolitical zones of the country. With a population of about 200, 000, 000 [15], margin of error of $5 \%$ (95\% CI), and vaccine acceptance of $50 \%$, we calculated a sample size of 385 [16], which was rounded up to a total of 410 by $10 \%$ attrition. Therefore, a total of 410 adults were invited for the survey. The study included both male and female Nigerians, persons who had access to internet facilities, and persons who belonged to online groups. It however excluded persons who did not provide informed consent for the study.

\subsection{Study Instrument}

Age, marital status, educational qualifications, place of residence and employment status are perceived to be major determinants of beliefs about vaccine. The questionnaire design was based on this theoretical frame work, and was composed of questions that explored and evaluated the socio-demographic characteristics of the respondents and their beliefs about COVID-19 vaccine.

A structured questionnaire which required few minutes to complete was designed using Google forms. The main constructs measured by the questionnaire were socio-demographic characteristics of the respondents, their beliefs about COVID-19 vaccine, and the association between respondents' sociodemographics and beliefs about COVID-19 vaccine. Section A of the questionnaire obtained information on respondents' socio-demographic characteristics, while section B elicited information on respondents' belief about a COVID-19 vaccine and was composed of 5 questions which were anchored on a 5-point Likert scale. In the Likert scale, $1=$ strongly disagree, $2=$ disagree, $3=$ undecided, $4=$ agree and $5=$ strongly agree. 
The questionnaire was validated by pretesting and face validity. Assessment of its content was done by 2 public health experts and 1 psychologist. The pretesting was conducted among 20 Nigerian adults of different demographics and this led to the modification of the questions to remove ambiguity. Cronbach's alpha was employed to ascertain the reliability of the questionnaire.

\subsection{Data collection}

The anonymous internet link was distributed to consenting participants from the six geopolitical zones of Nigeria through online platforms. Purposive and snowball approach were adopted in the distribution of the internet link via social media platforms.

\subsection{Data analysis and study outcome measures}

Descriptive statistics comprising frequencies and percentages was conducted using the SPSS version 24, for respondents' demographic characteristics. A chi-square analysis was performed to assess the associations before socio-demographic characteristics and beliefs about COVID-19 vaccine. Conbach's alpha was determined to assess the internal consistency of the questionnaire.

Respondents' belief was categorised as positive or negative. The questions which were anchored on a 5-point Likert scale ranged from "Strongly agree" to "Strongly disagree". "Strongly agree" and "Agree" were coded as 1, while Undecided", "Disagree" and "Strongly disagree" were coded as 0 . Weighted analysis on beliefs about the vaccine was carried out. The weighted score was totaled over 5 , and scores $\leq 2$ were coded as positive beliefs, while scores $\geq 3$ were coded as negative beliefs.

To assess the odds of demographic characteristics with beliefs about COVID-19 vaccine, binary logistic regression was also performed. The respondents' belief on COVID-19 vaccine was considered the dependent variable and socio-demographic characteristics were the independent variables at a 95\% confidence interval. $\mathrm{P} \leq 0.05$ was considered statistically significant. For the selection of the final model, a backward stepwise model selection approach was adopted at $\mathrm{P}$-value of 0.5 . Age, gender, marital status, educational qualification, employment status and geo-political zone, were included as explanatory variables. Receiver Operating Characteristic (ROC) curve for multiple independent variables was analysed by using the predicted probability. The area under the curve (AUC) of the ROC was computed to evaluate the performance of the model in clearly distinguishing between all the positive and negative class points correctly.

The primary outcome measure of the study was beliefs about a COVID-19 vaccine by the study participants. The secondary outcome measure was the predictive ability of socio-demographic variables to accurately determine beliefs about a COVID-19 vaccine.

Acknowledgements: This study was funded by the researchers.

Author contributions: Concept - C.O.I.; Design - C.O.I., O.H.E.; Supervision - C.O.I., O.H.E., C.N.A; Resources C.O.I., O.H.E., C.N.A.; Materials - C.O.I., O.H.E., C.N.A .; Data Collection and/or Processing - C.O.I. O.H.E., C.N.A.; Analysis and/or Interpretation -. C.O.I., O.H.E., C.N.A.; Literature Search -C.O.I.; Writing -C.O.I.; Critical Reviews C.O.I., O.H.E., C.N.A.

Conflict of interest statement: The authors declared no conflict of interest.

Ethics committee approval: Ethical approval was obtained from the Ethical unit of the Kwara State Ministry of Health and had the reference number $\mathrm{MOH} / \mathrm{KS} / \mathrm{EU} / 777 / 456$. Informed consent was obtained from the study participants prior to the study. Consent for participation in the study was implied by clicking on the link and submitting the completed anonymous form, and this was stated at the first part of the form. Confidentiality of the participants' information was also ensured during and after the study.

\section{REFERENCES}

[1] Wang D, Hu B, Hu C, Zhu F, Liu X, Zhang J, et al. Clinical characteristics of 138 hospitalized patients with 2019 novel Coronavirus infected pneumonia in Wuhan, China. JAMA. 2020; 323: 1061-1069.

[2] Zhou F, Yu T, Du R, Fan G, Liu Y, Liu Z, Xiang J, Wang Y, Song B, Gu X, Guan L, Wei Y, Li H, Wu X, Xu J, Tu S, Zhang Y, Chen H, Cao B. Clinical course and risk factors for mortality of adult inpatients with COVID-19 in Wuhan, China: a retrospective cohort study. Lancet. 2020; 395(10229): 1054-1062. [CrossRef]

[3] Iheanacho CO, Okwesilieze CN. Clinical outcomes of the pharmacological management of coronavirus disease 2019 
(COVID-19). J Basic Soc Pharm Res. 2020; 1(Suppl 1): S1-S15.

[4] Iheanacho CO, Odili VU, Eze UIH. Risk of SARS-CoV-2 infection and COVID-19 prognosis with the use of reninangiotensin-aldosterone system (RAAS) inhibitors: a systematic review. Futur J Pharm Sci. 2021; 7: 73. [CrossRef]

[5] Salali GD, Uysal MS. COVID-19 vaccine hesitancy is associated with beliefs on the origin of the novel coronavirus in UK and Turkey. Psychol Med. 2020; 19: 1-3. [CrossRef]

[6] World Health Organisation. Polio Eradication - A battle I fought with undiluted passion, says Professor Oyewale Tomori, a major player who made this feat possible. https:/ / www.afro.who.int. Accessed 11 December, 2020.

[7] Magadmi RM, Kamel FO. Beliefs and Barriers associated with COVID-19 vaccination among the general population in Saudi Arabia. BMC Public Health. 2020. (Pre-print). [CrossRef]

[8] Bertin P, Nera K, Delouvee S. Conspiracy beliefs, rejection of vaccination, and support for hydroxychloroquine: A conceptual replication-extension in the COVID-19 pandemic context. Frontiers Psychol. 2020; 11: 565128. [CrossRef]

[9] Leigh JP, Fiest K, Brundin-Mather R, Plontnikoff K, Soo A, Sypes EE, Whalen-Browne L, Ahmed SB, Burns KEA, Fox-Robichaud A, Kupsch S, Longmore S, Murthy S, Niven DJ, Rochwerg B, Stelfox HT. A national cross-sectional survey of public perceptions of the COVID-19 pandemic: Self-reported beliefs, knowledge, and behaviours. PloS ONE. 2020; 15(10): e0241259. [CrossRef]

[10] Lewandowsky S, Gignac GE, Oberauser K. The role of conspiracist ideation and worldviews in predicting rejection of science. PLOS ONE. 2015; 10(8): e0134773. [CrossRef]

[11] Jegede AS. What led to the Nigerian boycott of the polio vaccination campaign? PLoS Medicine. $2007 ; 4(3)$ : e73. [CrossRef]

[12] World Health Organisation. What influences vaccine acceptance: A model of determinants of vaccine hesitancy. www.who.int/1_Model_analyze_driversofvaccineconfidence_22_March.pdf. Accessed 13 December, 2020.

[13] Chukwuorji JC, Iorfa SK. Commentary on the coronavirus pandemic: Nigeria. Psychol Trauma: Theory, Res, Practice, Policy. 2020; 12(S1): S188-S190. [CrossRef]

[14] Rumun AJ. Influence of religious beliefs on healthcare practice. International Journal of Education and Research. 2014; 2(4): 37-48.

[15] World Bank. https://data.worldbank.org/indicator/SP.POP.TOTL?locations=NG. Accessed 13 December, 2020.

[16] Sample size calculator. https://www.calculator.net/sample-sizecalculator.html?type=1\&cl=95\&ci=5\&pp=50\&ps=200000000\&x=50\&y=22. Accessed 15 October 2020 .

[17] Biasio LR, Bonaccorsi G, LoriniC, Percorelli S. Assessing COVID-19 vaccine literacy: a preliminary online survey. Human Vaccines Immunotherapeutics. 2020. [CrossRef]

[18] Wang K, Wong ELY, Ho KF, Chueng AWL, Chan EYY, Yeoh EK, Wong SYS. Intention of nurses to accept and change of intention to accept seasonal influenza vaccination during the coronavirus disease 2019 pandemic: A cross sectional survey. Vaccine. 2020; 38(45): 7040-7056. [CrossRef]

[19] Murphy J, Vallieres F, Bentall RP. Psychological characteristics associated with COVID-19 vaccine hesitancy and resistance in Ireland and United Kingdom. Nature Communications. 2021; 12: 21. [CrossRef]

[20] Olomofe C, Soyemi K, Udomah BF, Owolabi AO, Ajumuka EE, Igbokwe MC, et al. Predictors of uptake of a potential COVID-19 vaccine among Nigerian adults. MedRxiv. (Pre-print) 2021. [CrossRef]

[21] Ayandele O, Okafor CT, Oyedele O. The role of Nigeria's faith-based organisations in tackling health crises like COVID-19. 2021. africaportal.org. Accessed on 26th February, 2021.

[22] Khan S, Rahman CKF, Haitha CV, Jose BB, Tiwari R, Dhama K. COVID-19 vaccine acceptance: beliefs and barriers associated with vaccination among the general population in India. J Exp Biol Agric Sci. 2020; 8(Spl-1-SARS-CoV-2): S210-S218. 2020.8(Spl-1-SARS-CoV-2). [CrossRef]

[23] Panda DS, Girl RJ, Nagarajappa AK, Basha S. COVID-19 vaccine acceptance, and concern of safety from public perspective in the state of Odisha, India. Hum Vaccin Immunother. 2021. [CrossRef]

[24] Iheanacho CO, Eze UIH, Adida EA. A systematic review of the effectiveness of BNT162b2 mRNA and ChAdOx1 adenoviral vector vaccines in the general population. Bull Natl Res Cent. 2021; 45: 150. [CrossRef] 